\title{
Pesquisa Psicanalítica: Da Transferência com a Psicanálise à Produção do Ensaio Metapsicológico
}

\author{
Cristiano Dal Forno ${ }^{1, *}$ (D) \& Mônica Medeiros Kother Macedo² ${ }^{\text {(D) }}$ \\ ${ }^{1}$ Pontifícia Universidade Católica do Rio Grande do Sul, Porto Alegre, RS, Brasil \\ ${ }^{2}$ Universidade Federal do Rio Grande do Sul, Porto Alegre, RS, Brasil
}

\begin{abstract}
RESUMO - São frequentes os debates acerca da epistemologia e potencialidade da pesquisa psicanalítica, especialmente em função da inserção da Psicanálise no âmbito universitário, sobremaneira em nível de pós-graduação. Em vista disso, o presente artigo propõe uma possível articulação entre três pilares que sustentam uma proposta de pesquisa psicanalítica, quais sejam, o pesquisador psicanalítico, sua transferência com a Psicanálise e a produção de saber metapsicológico ancorada no espaço de orientação universitária. Defende-se que um pesquisador psicanalítico, no exercício aqui proposto de três tempos do testemunho, a partir de sua transferência com a Psicanálise e no espaço de orientação da pesquisa - possibilitado pelo orientador psicanalista - torna possível a produção de um saber em Psicanálise.
\end{abstract}

PALAVRAS-CHAVE: pesquisador psicanalítico, pesquisa psicanalítica, transferência, ensaio metapsicológico

\section{Psychoanalytic Research: From Transference with Psychoanalysis to the Production of the Metapsychological Essay}

\begin{abstract}
There are frequent debates about epistemology and the potentiality of psychoanalytic research, due in large part to the insertion of Psychoanalysis in the university realm, especially at the graduate level. Therefore, this article proposes a possible articulation between three pillars that support a psychoanalytic research proposal, namely, the psychoanalytic researcher, his transference with Psychoanalysis, and the production of metapsychological knowledge anchored in the space of university guidance. It is argued that a psychoanalytic researcher, in the exercise proposed here with three testimony tenses, from its transference using Psychoanalysis and in the space of research guidance - made possible by the psychoanalytic advisor - allows the production Psychoanalytic knowledge.
\end{abstract}

KEYWORDS: psychoanalytic researcher, psychoanalytic research, transference, metapsychological essay

Adiscussão acerca da pesquisa psicanalítica demonstra-se um tema atual e, simultaneamente, evoca elementos relativos à história da Psicanálise. Se, por um lado, intensificamse, atualmente, os debates acerca da epistemologia e da potencialidade da pesquisa psicanalítica, muito em função da inserção da Psicanálise no âmbito universitário, sobremaneira em nível de pós-graduação (Dunker, 2011; Jardim \& Hernández, 2010; Lo Bianco, 2003; Macedo \& Dockhorn, 2015; Poli, 2008; Rosa \& Domingues, 2010), por outro lado, seu objeto de pesquisa e seu método de investigação se encontram cunhados desde suas origens, remetendo à clínica freudiana (Caon, 1999; Iribarry, 2003; Macedo \& Dockhorn, 2015). A pesquisa psicanalítica, ora praticada, carrega as marcas de seu desenvolvimento histórico, tendo se estabelecido a partir do reconhecimento da especificidade de sua área de atuação (Lo Bianco, 2003). Tal método não prescinde do essencial rigor e especificidade que lhe são característicos (Macedo \& Dockhorn, 2015).

É cada vez mais numerosa a presença de Laboratórios e Grupos de Pesquisa em Psicanálise na Universidade que objetivam garantir condições para que a produção de saber psicanalítico possa encontrar vias efetivas de circulação (Poli, 2008). Nessa perspectiva, referindo-se ao aumento da frequência de procura da pesquisa psicanalítica, Iribarry (2003) situa que muitos profissionais, ao optarem pelo caminho da pós-graduação, têm buscado pautar suas

\footnotetext{
*E-mail: cristiano.forno@pucrs.br

- Submetido: 03/07/2017; Aceito: 14/10/2018.
} 
investigações a partir da apropriação do método freudiano. Contudo, pondera o autor, são escassos os trabalhos que discorrem propriamente acerca de como realizar uma pesquisa psicanalítica. De tal proposição, decorre a importância de se estabelecer, com clareza, os pressupostos e os procedimentos inerentes ao exercício investigativo possibilitado pelo método psicanalítico.

A Psicanálise, segundo Sauret (2003), no meio científico, tem o privilégio de ser a única disciplina a não renunciar a dar a palavra ao sujeito, isto é, a não renunciar àquilo que constitui a particularidade deste. Dessa maneira, conforme situa a autora, a Psicanálise não poderia ser uma ciência ${ }^{1}$ como as outras e, simultaneamente, ser uma ciência do sujeito, visto que precisa comportar esse espaço para o particular, que fala uma língua diversa da matemática, contraditória em termos, como é o humano. Conforme Jardim e Hernández (2010), seja na ciência, em seu modelo experimental, seja na Psicanálise, as maneiras de conduzir uma investigação não são independentes de seu método, de modo que ambas se caracterizam por metodologias próprias. Para a ciência, a metodologia é a forma de produzir conhecimento, e para a Psicanálise, implica aquilo que permite construir um saber acerca da verdade e do desejo do sujeito.

Jardim e Hernández (2010) sustentam que a crítica que se dirige à Psicanálise, por sua falta de cientificidade, não deve ser assumida como o ponto nodal da discussão, levando em consideração que tal argumento toma por certo que qualquer iniciativa teórica e de investigação deve estar subsumida ao método científico positivista. Jardim e Hernández (2010) compreendem que a fragilidade dessa crítica se encontra no fato de ser autorreferenciada e mostrar uma digressão de argumentos reducionistas, tendo em conta que a Psicanálise não é uma ciência positivista, tampouco se encontram na natureza de seus fundamentos elementos para nisto se transformar.

Mesmo diante do considerável contraste nas diferentes formas de proceder na obtenção de conhecimento e saber, segundo Jardim e Hernández (2010), ciência e Psicanálise perfilam-se, sendo impensável o surgimento da última como prática e descoberta do Inconsciente por Freud - antes do nascimento da primeira, no século XVII. Com o objetivo de apresentar a noção de sujeito da ciência, as autoras remetem-se a Descartes - propriamente à proposição do Cogito - que inaugurou a ideia de sujeito enquanto correlato da ciência, situando no pensamento a possibilidade de existência, isto é, um sujeito fundado no pensamento e na consciência. Certamente, esse não é o sujeito para o qual se volta a Psicanálise, uma vez que a dimensão essencial de sua subjetividade ficaria de fora da equação.

1 Por ciência, no contraste com a proposição psicanalítica apresentada neste manuscrito, admite-se aquela de caráter positivista, em que o critério de verdade está diretamente relacionado à positividade do dado, oriunda das ciências naturais em seu modelo experimental.
Jardim e Hernández (2010), assim como Sauret (2003), numa clara alusão ao que foi amplamente discutido por Lacan ao longo de seu ensino, esclarecem que o sujeito da ciência nasce precisamente daquilo que é rechaçado pelo ideal da própria ciência, ou seja, a partir do rechaço a tudo que é inconsciente - que passa a ficar de fora da possibilidade de ser conhecido ou investigado pela ciência. Mais do que isso, é a partir da ciência que se declara inexistente o saber inconsciente. A Psicanálise, segundo concluem as autoras, funda-se, precisamente, a partir desse rechaço da ciência, à qual presta grande auxílio, na medida em que dá conta de uma dimensão de saber que a esta escapa. Ter como objeto de investigação o Inconsciente não se trata, portanto, de uma questão contingencial, mas essencial para a constituição da Psicanálise, no espaço aberto que lhe é deixado pela ciência. Se não existisse a ciência, não existiria, portanto, a Psicanálise.

Assim, Sauret (2003) situa que a Psicanálise é filha da ciência, referindo que ela não existiria sem a produção do sujeito da ciência. Isso significa dizer que aquilo que precisou ficar de fora do discurso da ciência, pela gritante incompatibilidade com o paradigma desta, constitui-se no esteio de sustentação do discurso da Psicanálise. A prática investigativa da Psicanálise quer incluir no campo, portanto, o Inconsciente forcluído pelo discurso científico, produzindo um saber singular sobre o sujeito. É nesse cenário que se desenha a pesquisa psicanalítica, voltada ao Inconsciente e à produção de um saber cujo paradigma não está atrelado às comprovações e generalizações da ciência, mas à consideração daquilo que esta precisa deixar de fora, isto é, o saber acerca da singularidade que escapa ao consciencialismo cartesiano e à lógica protocolar do "para todos".

Dessa maneira, a riqueza do método investigativo inaugurado por Freud oportuniza a Psicanálise estender-se a searas em que a escuta do singular remonta à clínica, mas não se limita ao seu setting tradicional. $\mathrm{Na}$ identificação com a capacidade criativa e inventiva de seu criador e na sustentação garantida por seu legado teórico aberto, encontra-se a vitalidade dessa proposta investigativa, bem como seu potencial de assumir as permanentes demandas de trabalho em prol da ampliação de suas possibilidades (Macedo \& Dockhorn, 2015).

Freud continua a ser o modelo de pesquisador psicanalítico (Caon, 1999), de maneira que, por meio do método de investigação do humano por ele fundado, a pesquisa psicanalítica vem ganhando, progressivamente, maior espaço no âmbito universitário, permitindo que pesquisadores identificados com a prática de escuta do singular e transferenciados com o legado freudiano possam produzir investigações e contribuir com o avanço do saber psicanalítico. Nesse sentido, o presente artigo propõe uma possível articulação entre três pilares que sustentam uma proposta de pesquisa psicanalítica, quais sejam, o pesquisador psicanalítico, sua transferência com a Psicanálise e a produção de saber metapsicológico ancorada no espaço de orientação universitária. 


\section{EM FREUD,AS DIRETRIZES DE PESQUISA E O MODELO DE PESQUISADOR PSICANALÍTICO}

Na obra de Freud podem ser encontrados o lastro teóricoepistemológico e as diretrizes que orientam a pesquisa psicanalítica, assim como a indicação dos imprescindíveis requisitos para a ação de seu pesquisador. Em Pulsões e destinos da pulsão, de 1915, conforme registra Caon (1999), encontra-se uma plataforma epistemológica e metodológica que, se didaticamente transposta, pode guiar os passos do pesquisador psicanalítico. $\mathrm{Na}$ abertura desse texto, são apresentados os passos da constituição de uma nova matriz teórica que precisou ser elaborada também como forma de sustentação para um novo campo de pesquisa. Nas palavras de Freud (1915/2004), lê-se:

Ouvimos muitas vezes a opinião de que uma ciência deve se edificar sobre conceitos básicos claros e precisamente definidos, mas, na realidade nenhuma ciência, nem mesmo a mais exata, começa com tais definições. $\mathrm{O}$ verdadeiro início da atividade científica consiste muito mais na descrição de fenômenos que são em seguida agrupados, ordenados e correlacionados entre si. Além disso, é inevitável que, já ao descrever o material, apliquemos sobre ele algumas idéias abstratas obtidas não só a partir das novas experiências, mas também oriundas de outras fontes. Tais idéias iniciais - os futuros conceitos básicos da ciência - se tornam ainda mais indispensáveis quando mais tarde se trabalha sobre os dados observados. (p.145)

Como esclarece Caon (1999), antes de qualquer coisa, Freud dedica-se ao estabelecimento de um dispositivo epistemológico específico como forma de dar sustentação às concepções da pesquisa psicanalítica, denominado de metapsicologia. $\mathrm{O}$ rigor metodológico que marca a prática freudiana evidencia-se na afirmativa de que a formulação mais precisa dos conceitos básicos de uma disciplina sempre deve ser buscada mediante novas descobertas. Segundo defende Freud (1915/2004), para que o conhecimento possa progredir, tais definições não podem ser rígidas, sendo a física - com seu admirável exemplo, em que os "conceitos básicos", mesmo que fixados em definições gerais, sofrem modificação em seu conteúdo - uma ilustração dessa maneira de proceder em ciência. Nessa referência, demonstra-se, com clareza, no modelo assumido por Freud, em seu procedimento investigativo, importantes recomendações à pesquisa psicanalítica.

Freud permanece, portanto, a ensinar pelo que produziu de próprio punho, na inoxidável riqueza de seus escritos, mas, também, em igual medida de relevância, pelo modelo de uma prática cunhada no rigor de um fazer profissional que se configurou na circunscrição de um campo próprio de pesquisa e intervenção, nunca renunciando à sua especificidade epistemológica, diversa da ciência tradicional. Nesse contraste, delineia-se que cada disciplina assume caminhos particulares na construção de sua própria racionalidade.
Chalmers (1993), quando se dedica a definir ciência, alerta que "não há uma categoria geral, 'a ciência', e nenhum conceito de verdade à altura de caracterizar a ciência como uma busca da verdade" (p.197). Esse epistemólogo, na medida em que sustenta que "cada área do conhecimento deve ser julgada por seus próprios méritos, pela investigação de seus objetivos, e, em que extensão é capaz de buscá-los" (Chalmers, 1993, p.197), aponta os perigos da hegemonia de um conceito único e atemporal de ciência servir de argumento para a exclusão ou supressão de diferentes áreas do saber. Fazendo frente à supremacia do pensamento consciencialista de seu tempo, Freud, mediante a delimitação de um campo e de um objeto específico, qual seja o Inconsciente, negligenciado pela ciência, viu-se diante do árduo desafio de produzir formas de apropriação e de saber sobre este, do qual sua clínica e sua obra dão notável testemunho.

Nesse sentido, segundo considera Lo Bianco (2003), a educação formal de Freud foi produzida no contexto das pesquisas acadêmico-científicas do final do século XIX, na qual ele foi instruído por mestres de marcada experiência experimental e orientação de caráter positivista. Indiscutivelmente, sua opção por desenvolver novos empreendimentos de pesquisa não é fruto de um desconhecimento do método experimental do laboratório, mas de "uma ousadia que o faz retirar-se das questões legítimas que eram colocadas por um mundo legítimo acadêmico-científico de finais de século" (Lo Bianco, 2003, p.118) para se dedicar à descoberta de meios de investigação mais apropriados à especificidade dos fenômenos que se lhe apresentavam.

Diante da constatação da existência de algo que, para além da consciência, estava a determinar os estados subjetivos, fertilizava-se o solo do qual surgiria, na teorização freudiana, a noção de Inconsciente e do desejo que influenciará o sujeito psicanalítico (Lo Bianco, 2003). Dessa maneira, a pesquisa laboratorial experimental, em que Freud havia sido capacitado, não mais lhe seria útil, precisando ele desenvolver um novo método de investigação para lidar com um objeto de outra natureza (Lo Bianco, 2003).

Nesse contexto de virada epistemológica produzida por Freud, Caon (1999) mostra que o surgimento do pesquisador psicanalítico "é condicionado pela passagem da pesquisa neuro-anatômica e neuro-anátomo-patológica [...] para a pesquisa psicopatológica stricto sensu, em que a atividade pesquisadora e a atividade clínica são uma e mesma coisa" (p. 38). Conforme destaca o autor, a virada realizada por Freud é mais do que uma transposição, produzindo uma mudança de paradigma, na medida em que "o aparelho neurológico é, agora, substituído pelo aparelho psíquico" (p. 39, grifo do autor). 
É, portanto, no campo da relação analítica que o Inconsciente passa a ser considerado e investigado. Todavia, sabidamente, seus efeitos não são exclusivos ao setting, tampouco se resumem a essa relação. A pesquisa psicanalítica começa na clínica, mais exatamente na clínica de Freud, estendendo seu método investigativo a outros espaços e fazendo valer sua epistemologia em uma nova concepção de sujeito a ser investigado pelo pesquisador psicanalítico nos mais variados contextos existenciais. Nessa perspectiva, de acordo com Aguiar (2006), a questão que se coloca não é clínica, senão epistemológica, de maneira que "tivesse a psicanálise o poder de curar todas as formas de patologia mental, ainda assim seu julgamento e reconhecimento viriam de sua contribuição ao saber enquanto ciência dos processos inconscientes" (p.122).

No presente contexto de aproximação da pesquisa em relação às diretrizes cunhadas na clínica, destaque merece, ainda, o texto freudiano intitulado Recomendações aos médicos que exercem a psicanálise, de 1912. Nesse escrito, Freud (1912/2006) dedica-se a apresentar alguns princípios para o exercício clínico psicanalítico, dos quais se avulta a recomendação da análise pessoal daquele que se propõe a analisar um outro. Entende-se que tal preceito, ainda que relativo ao contexto de tratamento, constitui-se, também, imprescindível ao campo da pesquisa psicanalítica, na qualidade de experiência possibilitadora da escuta do pesquisador psicanalítico.

Nesse texto, Freud (1912/2006) refere que, assim como o paciente é convidado a relatar tudo o que sua auto-observação possa detectar, evitando toda a censura intelectual e afetiva, o clínico deve colocar-se em condição de utilizar tudo o que lhe é comunicado para fins de interpretação, identificando o material inconsciente oculto, sem substituir sua censura pela seleção que o paciente prescindiu de realizar. Freud (1912/2006) exorta que, se o clínico pretende utilizar seu Inconsciente a seu favor na decodificação do Inconsciente do paciente, como instrumento de análise, deve preencher determinada condição, qual seja, aquela em relação a se analisar. Também refere que, para não introduzir na análise do que escuta qualquer atravessamento de seleção e deformação, é necessário que "tenha passado por uma purificação psicanalítica e ficado ciente daqueles complexos seus que poderiam interferir na compreensão do que o paciente lhe diz" (Freud, 1912/2006, p.129).
Assim, Freud (1912/2006) entende que todo aquele que assumir com seriedade o ofício clínico deve escolher o curso da análise pessoal como inegociável prioridade, obtendo desta experiência inúmeras recompensas. Contrariamente, aponta que quem não tomar a precaução de se analisar, não somente estará inapto a, efetivamente, escutar seus pacientes, mas estará assumindo o risco mais sério de, por meio da projeção, situar fora de si peculiaridades de suas próprias personalidades, levando o método psicanalítico ao descrédito.

Considera-se, na linha argumentativa desenvolvida no presente texto, que tais aspectos relativos ao tratamento clínico são extensivos à pesquisa psicanalítica, independentemente do local em que sua escuta será efetivada. Aguiar (2006), no contexto de discussão acerca de quem é o pesquisador psicanalítico, ressalta a importância da experiência de tratamento pessoal na prática deste profissional. Refere, ainda, que não se pode pesquisar sobre Psicanálise sem que se venha a ser, em alguma medida, nos limites da própria análise, um pesquisador psicanalítico - pesquisador da singularidade subjetiva e dos mecanismos inconscientes.

Claro está, assim, que Freud sempre foi e, indubitavelmente, segue a ser o modelo de pesquisador psicanalítico, que, ao oferecer sua escuta, lança-se em busca daquilo que está para além do aparente a ancorar a subjetividade daquele que, na transferência, encontra o espaço para se narrar e, com isso, elaborar sua história. De acordo com o que ressalta Caon (1999), orientado por Freud em seus textos metapsicológicos, o pesquisador psicanalítico encontra-se em posição de reconstruir o campo de conceitos metapsicológicos, já estabelecido pelos pesquisadores psicanalíticos que o precederam, de modo que, por meio de suas investigações, poderá propor novos conceitos ao campo da metapsicologia.

Contemporaneamente, a universidade tem se apresentado como um espaço profícuo de produção, no qual a maioria das pesquisas psicanalíticas têm se realizado. Em vista da progressiva ocupação desse espaço pela Psicanálise, que tem permitido, inclusive, sua interlocução com outros saberes, entende-se que, sobremaneira no âmbito da pesquisa psicanalítica realizada em nível da pós-graduação brasileira, a produção de conhecimento é acrescida de especial significância quando atrelada à produção metapsicológica.

\section{OS CAMINHOS DA PESQUISA PSICANALÍTICA: O LABOR DE UM OFÍCIO ANCORADO NATRANSFERÊNCIA}

Devido à característica do objeto psicanalítico - o Inconsciente -, é possível circunscrever, na situação de análise, o procedimento de pesquisa que tem na clínica seu principal ponto de apoio, a partir do qual Freud pode desenvolver sua metapsicologia (Lo Bianco, 2003; Oliveira \& Tafuri, 2012). Sendo assim, Caon (1994) declara que o método de pesquisa psicanalítica deve ser examinado à luz da situação psicanalítica de tratamento, da qual herda seu modelo. O que irá diferenciar a situação psicanalítica de pesquisa daquela de tratamento se refere, segundo o autor, "ao manejo da transferência", na medida em que nesta será dissolvida, enquanto naquela, será 
instrumentalizada na produção do texto metapsicológico resultante dos achados.

Dessa maneira, para que alguém se torne psicanalista ou pesquisador psicanalítico, é indispensável que tenha, em algum momento, sido analisante, isto é, tenha podido fundar a experiência psicanalítica por meio da vivência e da dissolvição do amor transferencial, artificialmente produzido na situação psicanalítica de tratamento (Caon, 1999). Da experiência de ter sido escutado advirão as condições para, por sua vez, ofertar a outrem uma escuta sustentada na transferência. A condição de ter sido paciente da técnica para depois ser profissional dessa mesma técnica é, segundo Caon (1999), constituinte e condição sinequa non em Psicanálise.

$\mathrm{Na}$ história da Psicanálise, o processo de formação do psicanalista foi tema de que muito se ocupou Sándor Ferenczi, situando a análise do analista como sua condição primordial. Em comparação com outros ramos científicos, segundo Ferenczi (1928/2011a):

A experiência psicanalítica mostra que, para praticar o ofício de psicólogo, não basta estabelecer uma relação lógica entre os conhecimentos e os dados experimentais; é indispensável, além disso, efetuar um estudo profundo da nossa própria personalidade e uma observação rigorosa das nossas moções psíquicas e afetivas. (p.238, grifo do autor).

A educação para o conhecimento e domínio de si mesmo, como compreende Ferenczi (1928/2011a), é a essência da formação do analista, de maneira que a formação teórica e prática somente podem se produzir na sequência. Desse modo, no contexto da capacitação de um sujeito que se propõe à análise de outros, Ferenczi foi o primeiro a estabelecer relação entre a formação do analista e o final de sua análise pessoal (Bernardes, 2002; Bertonzzin \& Abrantes, 2015).

No texto intitulado Elasticidade da técnica psicanalítica, Ferenczi (1928/2011b) enuncia a análise do analista como a segunda regra fundamental da Psicanálise. Do lado do paciente, a livre associação constituiria a primeira regra fundamental para que o Inconsciente pudesse apresentar suas formações no espaço da análise. Enquanto isso, do lado do analista, sua análise seria a condição de abertura para a escuta daquilo que surgiria na transferência, constituindo-se, portanto, como a segunda regra fundamental. Assim, na análise do analista, encontrar-se-ia o elemento fundamental que o habilitaria ao exercício da análise de outrem. De acordo com Ferenczi (1928/2011b), a dificuldade da ação do analista relaciona-se ao manejo da transferência, terreno que requer que ele seja analisado. Tal contribuição ferencziana ocorre no contexto clínico de tratamento, do qual a situação psicanalítica de pesquisa, conforme já demonstrado, herda seu modelo, sendo possível, dessa maneira, tornar sua recomendação extensiva ao ofício do pesquisador psicanalítico.

Sendo assim, pode-se afirmar que a pesquisa psicanalítica é relativa ao tempo de percurso e de formação de cada sujeito
(Poli, 2008). No amplo campo psicanalítico, o resultado do trabalho investigativo é dependente de até onde foi a análise do pesquisador. Trata-se de considerar que, para a ação investigativa do pesquisador psicanalítico, a análise pessoal é a base de sustentação de seu ofício.

Nessa mesma direção, Sauret (2003) entende que o método psicanalítico, no fundo, é constituído daquilo que, pela experiência da análise, pode ser transponível para fora desse contexto, estando composto de uma concepção de sujeito como falante e dividido, pela hipótese de Inconsciente como fundamento de todo o fato psíquico, o que implica operar com "verbalização (entrevista), escuta, análise, transferência, intervenção" (p.98). É, dessa maneira, que a experiência clínica, desde o lugar primordial de analisante e, posteriormente, de profissional da escuta, oportunizará ao sujeito pesquisador - psicanalítico - as condições necessárias à sua prática investigativa, tendo em conta, também, os paradigmas estabelecidos pelo trabalho daqueles pesquisadores que $\mathrm{o}$ antecederam.

Assim, pode-se concluir, com base em Caon (1999), que o exercício da Psicanálise nasce da clínica, propriamente do reclinamento sobre o divã, em que o psicopatológico é fundamento da investigação. $\mathrm{O}$ autor aproxima a situação psicanalítica de pesquisa (spp) da situação psicanalítica de tratamento (spt), indicando que aquela é uma situação que se orienta pelo modelo desta. Para o autor, portanto, a spp é a refundação da experiência inaugurada na spt. Por meio de tal refundação, abre-se a possibilidade de teorização metapsicológica, sustentada na experiência anterior de inserção no dispositivo epistemológico da Psicanálise, em que $o$ analisante se experimenta como o pesquisador daquilo que é inconsciente.

No esforço de construir uma definição que situe esta modalidade investigativa no âmbito da universidade, Caon (1999) refere que a pesquisa psicanalítica é:

A refundação, no campo das comunidades universitárias de pesquisadores, daquela experiência anteriormente fundada na situação psicanalítica de tratamento, onde o paciente analisante é o pesquisador, por excelência, e o psicanalista é o diretor dessas pesquisas, produzidas em método e procedimentos de associação livre, produzidas pelo paciente analisante em transferência e 'in praesentia' do psicanalista. (p. 40, grifo do autor)

$\mathrm{Na}$ aproximação que estabelecem entre certas características metodológicas da pesquisa psicanalítica e a estrutura narrativa do romance policial, Dunker et al. (2002) oferecem a ilustração do personagem Watson como metáfora do papel exercido pelo pesquisador psicanalítico. No romance de Arthur Conan Doyle, a investigação é conduzida por Sherlock Holmes, cabendo a John Watson a posição de discussão, testemunho e registro da experiência investigativa. É para ele que o detetive oferece argumentos, justifica-se e presta contas de suas ações. Dessa forma, cabe a Watson a função de redigir as aventuras e descobertas de Holmes. 
Tendo em conta a pesquisa psicanalítica no âmbito da universidade a partir da indagação de qual lugar falaria o pesquisador em seu texto, Dunker et al. (2002) concluem que, certamente, não é do lugar de analista, senão de "testemunha de uma experiência elaborada". Admitindo a proximidade estrutural existente entre a narrativa policial e a pesquisa psicanalítica, ambas marcadas pelo caráter investigativo conjectural e argumentativo, os autores postulam que $o$ lugar a partir do qual o pesquisador psicanalítico produz seu texto de relato da experiência analítica é muito próximo ao ocupado pelo personagem de Watson nas investigações de Holmes. É mostrado que "ele compartilha a experiência da investigação; é ele quem narra as memórias de Holmes; é para ele que os argumentos e justificativas de Holmes são expostos" (Dunker et al., 2002, p. 124). Entende-se, com isso, que, sem Watson, a pesquisa e a investigação policial perderiam sua estrutura essencial de diálogo, que busca a resolutiva de um enigma por meio de conjecturas que são criadas, debatidas e trazidas ao conhecimento público (Dunker et al., 2002).

Na metáfora de Sherlock Holmes e John Watson ilustrada, fica a constatação de que "quem faz a pesquisa é o participante", aos moldes da pesquisa feita pelo paciente deitado no divã, cabendo ao pesquisador a direção e o testemunho da investigação. Nesse ponto, situa-se a importância da escuta que, não necessariamente precisará vir de um psicanalista, mas de alguém que, ao já ter ocupado o lugar de analisante, encontra-se em condição de "escutar" e dar o "testemunho" desta experiência na forma do texto.

Chega-se, então, à proposição de como pode se produzir a pesquisa psicanalítica, ou seja, a de que seu modelo de pesquisa se refere ao "modelo do analisante", daquele que, no divã, realiza a pesquisa da vida. Por tal característica, o pesquisador se torna, desde o início, o primeiro sujeito da pesquisa que empreende. Da mesma forma como o analisante se engaja em seu processo de análise pessoal e diz algo de seu padecimento psicopatológico, no contexto de uma situação de transferência, "o pesquisador psicanalítico dá um testemunho de sua investigação a um outro, a uma alteridade com a qual também irá se "transferenciar"' (Iribarry, 2003, p.122). Novamente, o modelo seguido é o de Freud, que remetia suas elucubrações teóricas, em muitos momentos, à apreciação de Fliess, sendo os achados da pesquisa psicanalítica entregues à alteridade, na figura dos pares (Caon, 1994; Iribarry, 2003).

Em relação à subjetividade do pesquisador, que estará presente durante o processo de análise dos dados, Iribarry (2003) reporta-se ao conceito de solipsismo metodológico, proposto por Caon (1994), presente na pesquisa psicanalítica como uma forma de solipsismo em que, em lugar de uma restrição ao âmbito de uma experiência elementar e única, o que se observa, contrariamente, é a convocação de uma alteridade para comunicação desta experiência. Desse modo, segundo esclarece Iribarry (2003), o pesquisador psicanalítico comunica sua experiência à alteridade, isto é, ao público para o qual destina sua pesquisa.

\section{OS TRÊS TEMPOS DO TESTEMUNHO COMO ESTRATÉGIA METODOLÓGICA PARA A PESQUISA PSICANALÍTICA}

Neste ponto, portanto, delineia-se, neste artigo, como uma proposição metodológica possível à pesquisa psicanalítica, a existência de três tempos do testemunho, relativos ao oficio do pesquisador psicanalítico. O primeiro tempo ocorre na medida em que o pesquisador testemunha a narrativa realizada pelo participante da pesquisa; o segundo se dá no contexto da orientação/supervisão com o orientador psicanalista, em que o pesquisador procede à análise e à interpretação dos dados; o terceiro se refere à apresentação dos achados da pesquisa aos pares, permitindo a circulação do saber produzido, principalmente no âmbito acadêmico.

A proposição dos três tempos do testemunho como proposta metodológica alinha-se ao que afirma Iribarry (2003) sobre ser o pesquisador psicanalítico o primeiro sujeito de sua pesquisa. $\mathrm{O}$ autor defende a grande implicação que o pesquisador tem no trabalho que conduz, uma vez que é, por seu próprio punho, uma contribuição conceitual que irá se organizar no decorrer do processo investigativo. Tal fato não dispensa os demais participantes da pesquisa, mas demarca a inclusão e a importância do pesquisador também como sujeito da investigação.

Iribarry (2003) responde positivamente à pergunta sobre se o pesquisador psicanalítico seria movido por sua subjetividade ao analisar os dados de pesquisa, tendo em conta que suas impressões transferenciais resultam do modo como este se aproxima dos achados. O autor acrescenta, ainda, ser essa a mais legítima contribuição do percurso de Freud, mais movido sempre por suas tendências pessoais do que pelos dados de sua pesquisa, sendo "graças à sua interferência subjetiva que a psicanálise nasceu como uma teoria, um método e uma técnica de tratamento" (Iribarry, 2003, p.127). Nesse sentido, Freud foi autor e sujeito enquanto pesquisador psicanalítico (Caon, 1996).

Afirmar a presença de um autor que, através da posição de pesquisador, faz a experiência da investigação que dirige e dá testemunho não implica se entregar a um completo subjetivismo, tampouco à defesa de procedimentos aleatórios. Nesse sentido, Hornstein (2013), aproximando a epistemologia psicanalítica da lógica do pensamento complexo, considera que o método da Psicanálise encontra mais espaço de aproximação em relação à ciência contemporânea se comparada com a clássica, que se empenhava em eliminar o observador.

Dessa maneira, segundo o exemplo de Freud, "o tomar-se a si mesmo como paciente é um dos germes dessa posição, que, no campo da psicanálise, faz com que 
a técnica e a ética se equivalham" (Caon, 1999, p. 40). A posição do pesquisador psicanalítico é, antes, uma posição ética. A condução de uma pesquisa psicanalítica se pauta pela ética e pela especificidade de um campo que tem no sujeito de Inconsciente seu principal eixo norteador (Macedo \& Dockhorn, 2015; Dockhorn \& Macedo, 2008). São os elementos próprios a esse sujeito de Inconsciente que, segundo Macedo e Dockhorn (2015), sustentam a especificidade da Psicanálise, sendo, precisamente, diante da proposta de investigar tais elementos que deverá ocorrer o desenho da estratégia investigativa a ser assumida pelo pesquisador psicanalítico. As autoras ainda ressaltam que, no movimento de aliar o rigor metodológico e a especificidade que caracterizam a Psicanálise, o pesquisador poderá e, até mesmo, deverá criar estratégias de investigação que se pautem no paradigma freudiano, que, desde os primórdios, clarificou que a uma ciência que exclua o sujeito de Inconsciente não poderá se alinhar a epistemologia psicanalítica.
Nos três tempos do testemunho propostos neste artigo como possível estratégia metodológica de investigação, produzem-se os desdobramentos de uma prática de pesquisa que tem seu aporte fundamental na transferência com a Psicanálise, estabelecida pelo pesquisador psicanalítico, não necessariamente um psicanalista, em sua experiência de análise. A figura do orientador psicanalista apresentase como aquele que, por meio da prática de orientação/ supervisão, favorece condições para sustentar o processo de desvelamento e interpretação de novos achados e produção de novas ligações. No terceiro tempo do testemunho, a colaboração estabelecida entre o pesquisador psicanalítico e o orientador psicanalista fomenta condições ao exercício de interpretação dos achados da pesquisa, contemplando o rigor metodológico que sempre marcou o trabalho em Psicanálise. Como momento final, há a escrita do texto, que acrescenta ao material, também, novos elementos interpretativos e encontra seu inegável valor mediante o favorecimento da circulação entre pares do saber produzido em Psicanálise.

\section{ENSAIO METAPSICOLÓGICO:A ESCRITA DA PESQUISA PSICANALÍTICA}

A pesquisa psicanalítica descende do método psicanalítico, que encontra na figura do analisante o modelo de investigação da subjetividade e de construção de um saber sobre si próprio. Assim, conforme manifesta Caon (1999), o analisante, na qualidade de arqui-modelo do pesquisador psicanalítico, escreve-se com a tinta da própria voz, ofertando os elementos narrativos e transitórios que serão transformados em tempo paginado, pelo esforço inerente ao ato pontuador e escandidor da escuta psicanalítica. É nesse processo que, segundo Caon (1999), constitui-se a experiência psicanalítica, a qual, "no relance da situação psicanalítica de pesquisa (spp), pode transformar-se em texto de pesquisa psicanalítica, isto é, em ensaio metapsicológico" (p. 60). O ensaio metapsicológico apresenta-se, desse modo, como o possível texto, resultante da pesquisa psicanalítica, que terá na criativa obra escrita de um autor o registro e desfecho de um processo que se iniciou na transferência e na escuta de narrativas particulares, cabendo a indagação acerca dos caminhos a serem percorridos a fim de se alcançar tal destino.

Mediante o desafio de mapear possíveis caminhos, Iribarry (2003) ressalta, ao se dedicar a uma apresentação sistemática para atualização do método de pesquisa psicanalítica, que esta é tão somente uma resposta possível, que é necessária, porém não definitiva, para esse tipo de pesquisa. Fica, portanto, sinalizado um campo aberto para reflexão e novas apropriações do método.

Nesse sentido, Minerbo (2000) entende que a Psicanálise possibilitada por esse método, será, segundo a autora, sempre relativa ao processo de construção de um saber, de modo que tal processo, na qualidade de estratégia relativa a uma dada situação, será singular e irrepetível. Por não produzir verdades totalizantes, mas parciais, tal método garante espaço, no entendimento da autora, a novas empreitadas investigativas, orientadas pela criatividade do pesquisador.

Assim sendo, ainda que se lance a uma sistematização, apresentando os passos do processo psicanalítico de pesquisa, Iribarry (2003) reconhece que sua proposta trata de um recorte do modo como se apropriou do método freudiano de pesquisa, com vistas a inspirar aqueles que desejarem orientar suas pesquisas por meio da tradição psicanalítica de investigação. O que sempre estará em voga, então, será a apropriação particular do método de pesquisa psicanalítica pelo sujeito pesquisador. Nessa acepção, Iribarry (2003) demarca que o trabalho de análise, sobremaneira quando voltado à formação de um analista, priorizará o estilo e a marca singular daquele que se oferta como analista a um outro. Ele entende que tal lógica é extensiva à pesquisa psicanalítica, visto que esta sempre resultará da apropriação de um autor que, depois de tomar contato com o método de Freud, constituirá um método seu, que, mantendo-se filiado à vertente original, singularizará sua abordagem na realização de uma pesquisa.

Para comunicar a sua experiência de pesquisa, isto é, aquela decorrente dos procedimentos utilizados na coleta de dados, o pesquisador psicanalítico pode, segundo Iribarry (2003), recorrer a técnicas específicas para o tratamento dos dados. Tais técnicas seriam, segundo o autor, a leitura dirigida pela escuta e a transferência instrumentalizada. A leitura dirigida pela escuta refere-se a um dispositivo através do qual o pesquisador é capaz de identificar, no texto transcrito resultante da coleta de dados, contribuições particulares e diferenciadas daquelas já conhecidas, localizando elementos cujos sentidos podem assumir o caráter de uma contribuição para o problema de pesquisa que norteia a investigação. Por sua vez, a transferência 
instrumentalizada refere-se ao processo por meio do qual o pesquisador dirige-se aos dados de pesquisa, transcritos em forma de texto, analisando-os à luz da literatura que embasa a pesquisa. Além disso, o pesquisador procura "elaborar impressões que reúnem as suas expectativas diante do problema de pesquisa e as impressões dos participantes que forneceram suas contribuições na forma de dados coletados" (Iribarry, 2003, p.129).

A técnica de análise dos dados proposta por Iribarry (2003) baseia-se na leitura dos textos oriundos das transcrições do material obtido na coleta de dados, de onde o pesquisador irá retirar os subsídios para a construção do ensaio metapsicológico. Nessa técnica, conforme diferencia o autor, não há a manipulação de signos, como ocorre, por exemplo, na Análise de Conteúdo ou na Análise do Discurso. Nela, o pesquisador detém-se ao âmbito do significante e da abertura de sentidos que lhe é característica. É dessa forma que, de acordo com Iribarry (2003), o pesquisador psicanalítico encontra os elementos cruciais para a construção do ensaio metapsicológico, texto que compõe a parte de discussão dos dados, de forma a preparar as considerações finais do trabalho. Por essa via, o pesquisador psicanalítico oferece sua contribuição à compreensão e explicação da temática estudada por meio da interpretação e da ampliação de sentidos possíveis ao material coletado. É por isso que, como expõe Iribarry (2003), “são os significantes introduzidos pela experiência do pesquisador com o texto que irão oferecer novas significações, novos sentidos para o dado coletado e transformado em texto" (p. 128). Conforme assinala o autor, a responsabilidade pela produção final da pesquisa é inteiramente do pesquisador psicanalítico, e cada novo termo acrescentado ao texto e divulgado por meio do ensaio metapsicológico expande o horizonte de compreensão e explicação da temática estudada.

$\mathrm{Na}$ busca pelo estado da arte sobre pesquisa psicanalítica, encontram-se referências claras a Theodor Adorno (1974/1985), naquilo que para ele caracteriza um ensaio. Sua proposição de ensaio, como forma de expressão que considera a interação dos conceitos no processo da experiência, oferta-se como possibilidade de construção criativa. Por suas peculiares características, o ensaio, conforme proposto por Adorno (1974/1985), "não almeja uma construção fechada, dedutiva ou indutiva" (p. 174). Assim, essa forma de expressão serve de modelo para a elaboração do ensaio metapsicológico, o qual se configura como uma possível produção resultante da pesquisa psicanalítica (Caon, 1999; Iribarry, 2003; Pereira, 2006).

Nesse sentido, o ensaio, segundo Adorno (1974/1985), possui uma autonomia estética e questiona o modelo canônico e positivista de conteúdo. Para Iribarry (2003), a consistência do ensaio não nasce da retirada do sujeito, de sua suposta supressão em favor de uma possível neutralidade científica; o ensaio surge justamente da inclusão do sujeito e, por fim, revela um autor. O ensaio, ainda segundo Iribarry (2003), não se pretende objetivo, tampouco em sua construção interessa a verificação da tese defendida para que haja sua comprovação; o que interessa ao ensaio é o conjunto da experiência individual e sua potência criadora.

Como defende Adorno (1974/1985), o ensaio não apresenta um fechamento de fato. Da mesma forma que a realidade, de acordo com o autor, o ensaio é incontínuo e formado por rupturas; ao não ser conclusivo, sua totalidade caracteriza-se como um não-total. Por tais especificidades, 0 ensaio, então, demonstra-se como profícuo recurso para que algo possa ser enunciado acerca da subjetividade humana, por se aproximar da concepção de sujeito com a qual a Psicanálise trabalha, ou seja, a de sujeito de Inconsciente.

A escuta atenta às produções do Inconsciente caracteriza a especificidade da Psicanálise. Desde Freud, é sabido que o mais singular do sujeito aparece nas rupturas de um discurso lógico e contínuo. É na falha, no lapso, no chiste, no sintoma e no sonho que aquilo que é da ordem do Inconsciente é dado a conhecer. A escuta psicanalítica dirige-se, portanto, não à coerência, mas aos aspectos disruptivos de uma narrativa que revela um sujeito naquilo que ele é, precisamente, onde não pensa. Nesse sentido, Rosa (2004) afirma que "o método psicanalítico vai do fenômeno ao conceito" (p. 341), ao construir uma metapsicologia que é fruto da escuta psicanalítica. Aquilo que o pesquisador psicanalítico escuta como produção do sujeito em sua narrativa de si passa a ser o barro a ser moldado nas mãos hábeis do oleiro da palavra, possibilitando a abertura à criação de novos sentidos e conceitos.

Por essas razões, a Psicanálise pode encontrar no modelo do ensaio a forma de escrita que mais se aproxima dos seus pressupostos. Conforme expõe Poli (2008), a construção de um saber em Psicanálise passa por um mergulho do pesquisador psicanalítico na cena na qual se deixa apanhar pelo enigma de sua pesquisa e por uma produção que se mostra condizente com o lugar de onde ele fala, o que requer que o pesquisador abandone, desde o início do processo, suas certezas apriorísticas. Tudo isso implica, segundo a autora, situar o pesquisador psicanalítico no interior da Psicanálise, na sua transmissão e herança, para, a partir desse ponto, construir um saber singular.

Há, portanto, uma diferença estabelecida no método de pesquisa psicanalítica em relação às pesquisas desenvolvidas em outros campos, uma vez que não se busca a produção de conhecimento generalizável, mas sim a produção de um saber singular, no qual o Inconsciente esteja contemplado (Poli, 2008). Na procura por esse saber, o pesquisador psicanalítico é levado, como já mencionado anteriormente, a provar a invenção freudiana, assim como o faz na experiência de análise pessoal, submetendo-se ao método e ao procedimento da associação livre. Em seu percurso, Freud aplicou sobre si mesmo sua invenção, valendo-se da associação livre (Pereira, 2006) e testemunhando sobre sua experiência em textos e cartas (Aguiar, 2006). Agindo de tal forma, segundo Pereira (2006), Freud encontrou uma condição de máxima intimidade, que, contudo, o aproximou de maneira irrevogável de seus pacientes e, por conseguinte, de todos os seres falantes. Está claro para os estudiosos da 
Psicanálise que Freud procurou dar o testemunho daquilo que, para ele, fazia enigma, o que não o levou, entretanto, a cair em um "subjetivismo desenfreado" (Pereira, 2006).

A prática da pesquisa psicanalítica, conforme enunciado anteriormente, pressupõe a experiência de três tempos, que começa no testemunho da narrativa do participante - primeiro tempo -, e se encerra na apresentação dos resultados em forma de ensaio metapsicológico, aos pares - terceiro tempo. Há que se considerar a relevância do segundo tempo, um intermediário, que pontifica o princípio e a conclusão do exercício da pesquisa psicanalítica, a qual tem no espaço de orientação, sustentado pela transferência do pesquisador com o orientador psicanalista, importante campo criativo e que o resguarda do risco de ficar restrito ao plano de sua pessoalidade.

Nessa árdua tarefa de tentar transmitir algo da sua experiência de pesquisa, o pesquisador psicanalítico pode encontrar como aliado o recurso da construção do caso proposto por Fédida (1991). O caso, conforme situa o psicanalista, é formado por hipóteses meramente da ordem da fantasia, que são construídas nas sessões de supervisão. É na supervisão que se busca formar e formular o enigma do caso, a partir de um ponto de vista que é exterior à situação de pesquisa. Para que haja, concretamente, a construção do caso, na prática da pesquisa, é necessário que a supervisão/ orientação se apresente como um espaço de interlocução entre o pesquisador psicanalítico e o supervisor/orientador, que, nesse sentido, cumpre a função de alteridade na construção do caso.

Para Fédida (1991), a construção do caso de análise efetua-se em relação ao que é elaborado no decorrer do processo de supervisão e que passa a ganhar o status de caso propriamente dito somente no momento em que é apresentado publicamente à comunidade psicanalítica. Nesse sentido, o caso é, para o autor, o trajeto da formulação do enigma do caso, produzido nas sessões de supervisão até a sua apresentação diante dos pares. Sendo assim, o caso pode ser visto como uma teoria em gérmen que possui capacidade de transformação metapsicológica.

Destaca-se que, para Fédida (1991), a proposta de construção do caso é relativa ao campo eminentemente da clínica psicanalítica e se sustenta na relação transferencial do analista com seu supervisor clínico. No presente artigo, propõe-se que, em se tratando da produção de pesquisa psicanalítica na universidade, o orientador ocupe a função de alteridade na construção do caso, o qual se materializará, posteriormente, em forma de ensaio metapsicológico. Portanto, o papel exercido pelo orientador psicanalista, na situação psicanalítica de pesquisa, equivaler-se-á àquele do supervisor clínico na situação psicanalítica de tratamento. $\mathrm{Na}$ realização de uma pesquisa psicanalítica, o orientador surge como uma primeira alteridade encarnada, com quem o pesquisador psicanalítico, em transferência, construirá casos que serão, posteriormente, remetidos, na forma escrita de ensaios metapsicológicos, à apreciação dos pares que compõem as comunidades psicanalítica e universitária.

Conclui-se, desse modo, que na presença de um pesquisador psicanalítico, o qual se vale de sua transferência com a Psicanálise, ancorado em sua análise pessoal, no estudo da teoria e no espaço de orientação da pesquisa - possibilitado pelo orientador psicanalista - a produção de um saber em Psicanálise torna-se possível. Para tanto, fica evidenciada a importância da atenção às diretrizes metodológicas enunciadas nesta proposição dos três tempos do testemunho como possível estratégia para a realização de uma pesquisa psicanalítica.

\section{CONSIDERAÇÕES FINAIS}

Em sua descoberta do Inconsciente, a Psicanálise se propõe a construir um saber fora dos controles do laboratório e se interessa pela dimensão que escapa aos protocolos investigativos, apresentando-se como antítese à regra primaz do Cogito Cartesiano. Afirmar, todavia, um rompimento com o método da ciência, não implica em assumir a recusa de qualquer método na condução de suas investigações. $\mathrm{O}$ progresso da Psicanálise permitiu a circunscrição de seu objeto de estudo, com o estabelecimento das especificidades que permitem sua investigação e, concomitantemente, a criação de um método de exploração da singularidade humana que encontra no rigor da clínica fundada por Freud seu paradigma.

A caracterização do pesquisador psicanalítico aponta que, em primeiro plano, está a efetiva condição deste de se lançar à experiência de escuta da subjetividade. $\mathrm{Na}$ experiência de antes ter sido tomado como analisante e escutado, está estruturada, portanto, a condição daquele que, agora na posição de pesquisador psicanalítico que dirige a investigação, escuta a pesquisa empreendida por um outro e desta dá testemunho em três tempos distintos, mas relacionados.

Delineia-se, assim, que o elemento determinante da utilização do método de investigação psicanalítica é relativo muito antes à experiência de ter sido escutado na posição de analisante e, a partir disso, poder silenciar internamente e escutar outrem na incursão investigativa que este fará, do que propriamente ter sido reconhecido formal e institucionalmente como psicanalista. Dito de outra forma, o exercício da escuta, na investigação psicanalítica, diz de uma condição a ser ocupada mediante a sustentação de uma transferência daquele a quem se dirige a escuta e, principal e assumidamente, de uma transferência para com a Psicanálise como teoria, método e técnica que orienta um fazer profissional. É nesse sentido que, conforme recomendado por Sigmund Freud e consagrado por Sándor Ferenzci, sob a pecha de segunda regra fundamental, a análise do analista é condição tanto à escuta e manejo da transferência no 
tratamento clínico quanto na escuta e instrumentalização da transferência na pesquisa psicanalítica, proposição central defendida neste trabalho.

O Inconsciente, a livre associação, a escuta e a transferência constituem-se, assim, em elementos essenciais e inegociáveis do fazer psicanalítico, em sua dimensão de tratamento do psicopatológico, sendo onipresentes também no contexto da pesquisa psicanalítica, independentemente do espaço e do material sobre o qual essa se valha para se efetivar. Destaca-se, de forma especial, que a apropriação singular do método psicanalítico é marca indelével dessa abordagem de pesquisa, não havendo, portanto, um protocolo a ser executado. Cabe ao pesquisador, desse modo, lançar mão de sua singularidade no labor de produção de um saber que encontra na narrativa do participante de pesquisa a matéria prima do ensaio que se constituirá em forma de novas contribuições ao campo da metapsicologia.

Valendo-se, para tanto, da transferência com a Psicanálise, no espaço de criação possibilitado pela orientação, o pesquisador psicanalítico dedicar-se-á à construção do caso, que será sempre uma ficção, elaborado na forma de ensaio metapsicológico. Por fim, no exercício de uma ética que possibilita exercer uma posição investigativa a partir dos três tempos do testemunho, a prática do pesquisador psicanalítico e a produção de um saber ancora-se acerca do singular do sujeito ao qual direciona a escuta.

\section{REFERÊNCIAS}

Adorno, T. L. W. (1985). O ensaio como forma. In T. L. W. Adorno (Org.), Antologia (pp. 167-187). Ática. (Trabalho original publicado em 1974)

Aguiar, F. (2006). Questões epistemológicas e metodológicas em psicanálise. Jornal de Psicanálise, 39(70), 105-131. http://pepsic.bvsalud.org/scielo.php?script=sci_arttext\&pid $=\mathrm{S} 0103-58352006000100007$

Bernardes, A. C. (2002). A segunda regra fundamental: Um comentário sobre o Ferenczi de Lacan. Ágora, 5(2), 311-316. https://doi.org/10.1590/S1516-14982002000200007

Bertonzzin, M. H., \& Abrantes, T. (2015). O lugar do analista e do analisando em Ferenczi. Jornal de Psicanálise, 48(89), 137154. http://pepsic.bvsalud.org/scielo.php?script=sci arttext\& pid $=$ S0103-58352015000200012

Caon, J. L. (1994). O pesquisador psicanalítico e a situação psicanalítica de pesquisa. Psicologia: Reflexão e Crítica, $7(2), 147-174$

Caon, J. L. (1999). O pesquisador psicanalítico e a pesquisa psicanalítica. In J. A. T. Machado (Org.), Filosofia e psicanálise: Um diálogo (pp. 35-73). Edipucrs.

Caon, J. L. (1996). Psicanálise $<>$ metapsicologia. In A. Slavutzky, C. L. S. Brito, \& E. L. A. Souza (Orgs.), História, clínica e perspectiva nos cem anos da psicanálise. Artes Médicas.

Chalmers, A. F. (1993). O que é ciência afinal? Editora Brasiliense.

Dockhorn, C., \& Macedo, M. (2008). A complexidade dos tempos atuais: Reflexões psicanalíticas. Revista Argumento Psicologia, 26(54), 217-224.https://periodicos.pucpr.br/index.php/ psicologiaargumento/article/view/19815

Dunker, C. I. L., Assadi, T. C., Bichara, M. A. M., Gordon, J., \& Ramirez, H. H. A. (2002). Romance policial e pesquisa em psicanálise. Interações, 7(13), 113-126. http:// pepsic.bvsalud.org/scielo.php?script=sci_arttext\&pid $=$ S1413-29072002000100008

Dunker, C. I. L. (2011). Estrutura e constituição da clínica psicanalítica. Annablume.

Fédida, P. (1991). A construção do caso. In P. Fédida (Org.), Nome, figura e memória: A linguagem na situação psicanalítica. Escuta.

Ferenczi, S. (2011a). O processo da formação psicanalítica. Psicanálise IV. (A. Cabral, Trad.; $2^{\mathrm{a}}$ ed.). Editora WMF Martins Fontes. (Trabalho original publicado em 1928)

Ferenczi, S. (2011b). Elasticidade da técnica psicanalítica. Psicanálise IV. (A. Cabral, Trad.; $2^{\mathrm{a}}$ ed.). Editora WMF Martins Fontes. (Trabalho original publicado em 1928)

Freud, S. (2006). Recomendações aos médicos que exercem a psicanálise. In J. Strachey (Ed. e Trad.), Edição standard brasileira das obras psicológicas completas de Sigmund Freud
(Vol.12, pp.125-133). Imago. (Trabalho original publicado em 1912)

Freud, S. (2004). Pulsões e destinos da pulsão. In L. A. Hanns (Ed. e Trad.), Escritos sobre a psicologia do inconsciente (Vol. 1, pp. 133-173). Imago. (Trabalho original publicado em 1915)

Hornstein, L. (2013). Las encrucijadas actuales del psicoanálisis: Subjetividad y vida cotidiana. Fondo de Cultura Econômica.

Iribarry, I. N. (2003). O que é pesquisa psicanalítica? Ágora, 6(1), 115-138. https://doi.org/10.1590/S1516-14982003000100007

Jardim, L. L., \& Hernández, M. C. R. (2010). Investigación psicoanalítica en la universidad. Estudos de Psicologia, 27(4), 529-536. https://doi.org/10.1590/S0103-166X2010000400010

Lo Bianco, A. C. (2003). Sobre as bases dos procedimentos investigativos em psicanálise. Revista PSICO USF, 8(2), 115-123. https://doi.org/10.1590/S1413-82712003000200003

Macedo, M. M. K., \& Dockhorn, C. N. B. F. (2015). Psicanálise, pesquisa e universidade: Labor da especificidade e do rigor. Perspectivas en Psicología: Revista de Psicología y Ciencias Afines, 12(2), 82-90. https://www.redalyc.org/articulo. oa? id $=483547667010$

Minerbo, M. (2000). Estratégias de investigação em psicanálise. Casa do Psicólogo.

Oliveira, N. R., \& Tafuri, M. I. (2012). O método psicanalítico de pesquisa e a clínica: Reflexões no contexto da Universidade. Revista Latinoamericana de Psicopatologia Fundamental, 15(4), 838-850. https://doi.org/10.1590/S141547142012000400007

Pereira, R. F. (2006). Litoral, sintoma, encontro - quase ensaio. Revista da APPOA, 30(2),53-68. https://appoa.org.br/uploads/ arquivos/revistas/revista30-2.pdf

Poli, M. C. (2008). Escrevendo a psicanálise em uma prática de pesquisa. Estilos da Clínica, 13(25), 154-179. http:// pepsic.bvsalud.org/scielo.php?script $=$ sci_arttext\&pid $=$ S1415-71282008000200010

Rosa, M. D. (2004). A pesquisa psicanalítica dos fenômenos sociais e políticos: Metodologia e fundamentação teórica. Revista Mal-estar e Subjetividade, 4(2), 329-348.http:// pepsic.bvsalud.org/scielo.php?script $=$ sci_arttext\&pid $=$ S1518-61482004000200008

Rosa, M. D., \& Domingues, E. (2010). O método na pesquisa psicanalítica de fenômenos sociais e políticos: A utilização da entrevista e da observação. Psicologia \& Sociedade, 22(1), 180-188. https://www.scielo.br/pdf/psoc/v22n1/v22n1a21.pdf

Sauret, M. J. (2003). A pesquisa clínica em psicanálise. Psicologia USP, 14(3), 89-104. https://doi.org/10.1590/S010365642003000300009 